\title{
O uso de energia elétrica nas Universidades Federais Brasileiras, sob o enfoque do Plano de Gestão de Logística Sustentável
}

\author{
The use of electrical energy in Brazilian Federal Universities as long as the Sustainable Logistics \\ Management Plan Approach
}

\author{
Elton Jorge da Silva' \\ José Carlos de Jesus Lopes" \\ Rosamaria Cox Moura Leite Padgett"II \\ Jeovan de Carvalho Figueiredo ${ }^{\mathrm{IV}}$ \\ Erlaine Binottov \\ Frederico Fonseca da Silva ${ }^{\mathrm{VI}}$
}

\section{Resumo}

O Plano de Gestão Logística Sustentável (PLS) é uma das iniciativas do Governo Federal brasileiro para promover a racionalização de gastos e práticas sustentáveis na Administração Pública. O objetivo deste trabalho foi avaliar, nas implementações do PLS das Universidades Federais brasileiras (UF), as ações vinculadas ao tema mínimo energia elétrica. Foram coletados os PLS, os Planos de Ações (PA) e os respectivos Relatórios de Acompanhamento (RA) de todas as UF. As ações foram classificadas em categorias, criadas com base na literatura e na legislação que versa sobre o uso de energia elétrica no setor público e nas UF. A análise dos documentos revelou que menos da metade das UF não têm cumprindo as determinações legais impostas, principalmente no que diz respeito à publicação de documentos. Verificou-se também que apesar dos PA contemplarem, em grande parte, as categorias criadas, os RA demonstram que o sucesso na implementação das ações não é alto.

Palavras-chave: Administração Pública; Práticas Sustentáveis; Energia Elétrica; Sustentabilidade; Energia Renovável

\section{Abstract}

The Sustainable Logistics Management Plan (SLMP) is one of the initiatives of the Brazilian Federal Government to promote the rationalization of spending and sustainable practices at Public Administration. So, this research aims to evaluate, as far as the PLMS implementation of Brazilian Federal Universities (FU), actions related to the minimum electric energy theme. The SLMP, the Action Plans (AP), and the Follow-up Reports (FR) of all FU were collected as well in order to answer the central question. The actions were classified into categories, created based on the literature and legislation that deals with the use of electric energy in the public sector, mainly at the FU. The analysis of the documents appointed that half of the UF have not complied with the legal determinations imposed, mainly in what concerns the publication of documents. In addition, although the AP contemplate, most of the created categories, the FR demonstrate that the success in the implementation of the actions is not high.

Keywords: Public Administration; Sustainable Practices; Electricity; Sustainability; Renewable Energy

\footnotetext{
Universidade Federal de Mato Grosso do Sul, Campo Grande, Brasil. E-mail: elton.silva@ufms.br

Universidade Federal de Mato Grosso do Sul, Campo Grande, Brasil. E-mail: jose.lopes@ufms.br

I"I Universidade Federal de Mato Grosso do Sul, Campo Grande, Brasil. E-mail: rosamariamouraleite@gmail.com

ıv Universidade Federal de Mato Grosso do Sul, Campo Grande, Brasil. E-mail: jeovan.figueiredo@ufms.br

$\checkmark$ Universidade Federal da Grande Dourados, Dourados, Brasil. E-mail: erlainebinotto@ufgd.edu.br

vı Instituto Federal do Paraná, Curitiba, Brasil. E-mail: frederico.silva@ifpr.edu.br
} 


\section{Introdução}

Frente à preocupação mundial com o meio ambiente, o aquecimento global e as mudanças climáticas, a busca pela sustentabilidade tornou-se a principal alternativa para reduzir o impacto gerado ao meio ambiente ao longo do desenvolvimento econômico (PUCRS, 2010). A conservação dos recursos naturais, a exemplo do uso racional de energia elétrica e a gestão do meio ambiente nos empreendimentos privados e públicos passaram a ocupar posição de maior relevo nas políticas públicas nacionais, nos organismos internacionais e nas investigações dos meios acadêmicos (LEITE, 2013). Para Harring, Lundholm e Torbjörnsson (2017), os problemas de degradação ambiental implicam uma demanda crescente de coordenação e direção pelas autoridades públicas, pois são muitas vezes conceitualizados em termos de dilemas de ação coletiva. Os autores ressaltam ainda que, na formação da atitude ambiental, a educação é, muitas vezes, reivindicada como um fator importante.

Milano (2018) explica que as fontes de energia classificadas como renováveis, costumeiramente estão ligadas ao conceito de energia limpa, pois se comparadas com fontes tradicionais como petróleo, gás e carvão, praticamente não geram resíduos ou emissão de poluentes, além de seus impactos ambientais serem muito baixos. Para ele, ao citar Villalva (2015), defende a corrente que afirma que as fontes renováveis de energia são consideradas inesgotáveis para os padrões humanos de utilização, a exemplo da energia solar, eólica, hidrelétrica, das marés, geotérmica e da biomassa. Ainda para Milano (2018, p. 2) "com incentivos governamentais como linhas de crédito bancário para projetos com utilização de energias renováveis, isenção parcial ou total de impostos de importação dos equipamentos destinados a estes projetos e normas técnicas/regulamentações condizentes com a realidade brasileira”.

Contudo, uma outra corrente contrária a de Milano (2018) e Vilalva (2015), a qual pertence Krause et al (2002), adverte que a produção e o consumo de energia estão na origem de uma parte importante dos impactos das atividades humanas sobre o meio ambiente. Da mesma forma, Marques et al. (2006) salientam que o consumo de energia proveniente de diversas fontes (petróleo, carvão mineral, gás natural, energia elétrica, biomassa) é uma das principais causas de degradação do meio ambiente. Ainda neste sentido, Ferreira et al (2018), igualmente se colocam dizendo que é importante apontar que o homem não pode ver a natureza como uma fonte de recursos infinitos que podem ser intensivamente devastados para satisfazer a necessidade do consumo que precisa ser atendido de forma racional, com a preservação da flora, fauna, água e fontes preciosas de materiais.

Assim sendo, as demandas da sociedade são claras no tocante ao conforto que a energia, em suas diversas formas, proporciona. Por fim, para Fonseca Neto et al (2017, 134) se colocam,

Por assim entender, podemos referir que para garantir o desenvolvimento das sociedades, abandonadas as adjeti- vações comumente acrescidas ao termo desenvolvimento, precisamos pensar o desenvolvimento sob a ótica do pressuposto da sustentabilidade (social, econômica, ambiental, cultural, política, ética etc.). E, assim, congregar preocupações que refletem, justamente, suas diversas dimensões, na perspectiva de garantir um futuro previsível.

É no âmbito dessas discussões, que prezem pela lógica da sustentabilidade, as energias renováveis aparecem como novas fontes de energias, que embora ainda de forma tímida, já começa a constituir as matrizes energéticas de diversos países, a ponto que as

Renewable energy sources are somewhere between 15\% to $20 \%$ of world's total energy supply demand. A major part of this supply is dominated by traditional biomass which is mostly fuel wood and another large contribution is obtained by hydropower where nearly $20 \%$ of the global electricity supply is covered by this source. A small portion of this supply is currently contributed by new renewable energy sources such as solar energy, modern bio-energy, wind energy, geothermal energy and small hydropower (LORI \& LEMAN, 2016, p. 781).

Neste sentido, também nos entendimentos de Collaço; Bermann (2017) passou a ser urgente pensar, criar e construir novas práticas/fontes que levem para comunidades respostas às suas demandas de recursos naturais e de energia, de maneira a colaborar com os problemas ambientais emergentes. Sob este contexto, Menkes (2004) afirma que a Eficiência Energética (EE) vem se tornando cada vez mais um ponto recorrente nas discussões sobre a demanda de energia, mesmo quando de fonte renovável, em nível global e possui hoje um papel preponderante nas políticas mundiais de energia e de meio ambiente, em especial naquelas relacionadas às mudanças climáticas.

A aprovação, em novembro de 2014, do Plano de Ação para a Eficiência Energética do G20 (EEAP) demonstra a preocupação mundial com a questão energética e, consequentemente, com a sustentabilidade. Este é um Plano prático para fortalecer a colaboração voluntária de EE de forma flexível, permitindo que os países compartilhem conhecimentos, experiências e recursos, escolhendo as atividades preferenciais que melhor refletem suas prioridades domésticas (IPEEC, 2014).

As autoridades brasileiras, também preocupadas com essas questões, vêm adotando uma série de políticas públicas, desde a década de 1980, com edições de medidas legais, sobretudo, na área energética, com a criação do Programa de Conservação de Energia (CONSERVE), através da Portaria do Ministério da Indústria e do Comércio MIC/GM-46 de 1981(PICCINI, 1994) e com a instituição do Programa Nacional de Conservação de Energia Elétrica (PROCEL), pela Portaria Interministerial $n$ ํ 1.877, de 30 de dezembro de 1985, ambas com a finalidade de promover o uso eficiente da energia elétrica, combatendo o desperdício e reduzindo os custos de energia (BRASIL, 1985).

Essas medidas culminaram com a criação do Plano de Gestão de Logística Sustentável (PLS), instituído pela 
Instrução Normativa no 10 (IN 10/2012), de 12 de novembro de 2012, do Ministério do Planejamento, Orçamento e Gestão (MPOG), e disciplinado pelo Decreto no 7.746 , em 5 de julho de 2012 (BRASIL, 2012). De acordo com Brasil (2012), o PLS é uma ferramenta que permite à Administração Pública federal direta, autárquica e fundacional e às empresas estatais dependentes, estabelecer práticas de sustentabilidade e racionalização de gastos. O PLS deve apresentar as declarações dos objetivos e responsabilidades definidas, ações, metas, prazos de execução, além de mecanismos de monitoramento e avaliação.

O PLS deverá contemplar sete temas. São eles: 1) Material de Consumo; 2) Energia Elétrica; 3) Água e Esgoto; 4) Coleta Seletiva; 5) Qualidade de Vida no Ambiente de Trabalho; 6) Compras e Contratações Sustentáveis; 7) Deslocamento de Pessoal (BRASIL, 2012). As Universidades Federais brasileiras (UF) estão entre as entidades da Administração Pública que devem atender ao regulamento da referida IN 10/2012. Entre elas aqui, as que determinam que os PLS, os Planos de Ações (PA) e os respectivos Relatórios de Acompanhamento (RA) apresentem as metas alcançadas e as medições dos resultados obtidos a serem publicados, nos sites oficiais dos respectivos órgãos.

Diante deste contexto, indaga-se, uma vez que todas as UF também devem elaborar e publicar seus PLS, PA e seus respectivos RA, buscou-se responder a seguinte questão, que se torna a problemática central desta investigação científica: De que forma as Universidades Federais brasileiras estão implementando as iniciativas de Eficiência Energética e a Conservação de Energia em seus Planos de Gestão Logística Sustentável? Diante da problemática central anunciada, o objetivo geral desta pesquisa foi avaliar, nas implementações dos Planos de Gestão de Logística Sustentável das Universidades Federais brasileiras, as iniciativas vinculas à energia elétrica.

Para atingir este objetivo, foram coletados os PLS, os $\mathrm{PA}$ e os respectivos RA divulgados pelas UF, sob as quais, as ações voltadas ao uso de energia foram classificadas e analisadas. Para que o objetivo declarado seja atendido, este corpo textual tem início com esta parte introdutória. Em seguida, apresenta-se o Referencial Teórico. Logo após é explicada a Metodologia aplicada, que permitiu obter aos resultados e as discussões pertinentes apresentadas, a seguir. Por fim, as Considerações Finais são colocadas, acompanhadas das Referências Bibliográficas que deram todo o suporte teórico e discursivo desta pesquisa.

\section{Referencial teórico}

\section{A Importância da Energia Elétrica}

No início do Século XIX, ter eletricidade resultava do sucesso econômico, bem como considerava-se como prova da riqueza de uma determinada pessoa ou região. A energia elétrica era vista, inicialmente, como um bem de luxo, acessível apenas aos indivíduos e regiões mais ricas (PINTO JUNIOR, 2016). De acordo com a Resenha Energética Brasileira, no final do ano de 2016, apenas
0,5\% dos domicílios brasileiros particulares permanentes não tinham acesso à eletricidade (BRASIL, MME, 2017).

De acordo com a Agência Nacional de Energia Elétrica - ANEEL (BRASIL ANEEL, 2008), o consumo de energia é um dos principais indicadores do desenvolvimento econômico e do nível de qualidade de vida de qualquer sociedade, refletindo o ritmo de atividade dos setores industrial, comercial e de serviços, bem como a capacidade da população para adquirir bens e serviços tecnologicamente mais avançados, eletrodomésticos e eletroeletrônicos. O Atlas de Energia Elétrica do Brasil (BRASIL, ANEEL, 2008) aponta que, embora a expansão acentuada do consumo de energia possa refletir o aquecimento econômico e a melhoria da qualidade de vida, aspectos negativos como a possibilidade do esgotamento dos recursos utilizados para a produção de energia e o impacto ao meio ambiente produzido por essa atividade acompanham essa expansão.

Pinto Junior (2016) aponta que a política energética de todos os países preocupa-se com a segurança do abastecimento energético e com a busca do Desenvolvimento Sustentável (DS), com atenção justificadamente crescente para o tema dos impactos ambientais da produção e uso de energia. Ainda para o autor, criou-se uma equação em que de um lado da balança pesa a importância da energia e do outro pesa a preocupação com o meio ambiente. Diante dos impactos negativos da produção e do consumo de energia, a EE tem se tornando cada vez mais um ponto recorrente nas discussões sobre a demanda de energia, em nível global, e possui um papel preponderante nas políticas mundiais de energia e de meio ambiente, em especial naquelas relacionadas às mudanças climáticas (MENKES, 2004).

Em termos econômicos, a EE abrange todas as mudanças que resultam na diminuição da quantidade de energia utilizada em uma atividade, ou para atender aos requisitos de energia para um determinado nível de conforto. Neste caso, está associada à eficiência econômica e inclui mudanças tecnológicas, comportamentais e econômicas (WEC, 2004). Em concordância com esse conceito, Brasil (2007, p.135) reforça que a EE é interpretada como a economia de energia gerada para executar a mesma atividade antes realizada, seja pelo uso de um equipamento mais eficiente, ou mesmo de uma nova tecnologia, ou apenas pelo uso racional da energia.

Os mecanismos de implementações da EE são amplamente divididos pela literatura em: 1) Mecanismos de Base Tecnológica; e 2) Mecanismos de Base Comportamental. Sobre esta classificação, Nogueira (2007, p.93) esclarece que,

1. Mecanismos de base tecnológica: consiste no uso de novos processos e utilização de novos equipamentos que permitam reduzir as perdas de energia, por exemplo: a troca de lâmpadas incandescentes, que têm baixa eficiência, por lâmpadas de LED, que têm muito mais eficiência;

2. Mecanismos de base comportamental: fundamentam-se em mudanças de hábitos e padrões de utilização, a mudança de comportamento, por si só, tem a capacidade de promover a EE sem necessariamente fazer alterações técnicas. 
Os mecanismos de base tecnológica incluem a substituição energética. Neste caso, uma fonte de energia é substituída por outra menos competitiva, mesmo que esta não gere redução de perdas, tais como é a cogeração ou a substituição de chuveiros elétricos ou aquecimento de água a gás, por aquecimento de água solar (BRASIL, 2007). De acordo com Monteiro e Rocha (2005), as ações que dão ênfase em conscientização, educação e treinamento, ou seja, não tecnológicas, deverão ter custos menores que as ações de atualização tecnológica. Em geral, essas ações resultam em uma redução do consumo de energia, da ordem de $5 \%$, após o período de um ano, tendo um custo inferior a $1 \%$ do custo total de um Programa de Gestão Energética Global.

A promoção da EE pode também ser feita por meio de medidas administrativas. Marques et al. (2006) salientam que medidas administrativas muito simples podem ter um impacto significativo, reduzindo os efeitos nocivos à economia decorrentes do uso irracional da energia, e produzindo efeitos benéficos ao meio ambiente e à qualidade de vida das pessoas. Estas medidas não envolvem o uso de novos equipamentos ou a modificação de comportamento dos usuários, limitando-se a intervenções de ordem administrativa, como adequações de contratos de fornecimento.

\section{O Uso de Energia Elétrica nas Instituições de Ensino Superior}

As Instituições de Ensino Superior (IES), universo em que as UF estão inseridas, são cada vez mais cobradas pela sociedade, em função de serem responsáveis por disseminar mudanças em prol da sustentabilidade, seja por meio do ensino, pesquisa, extensão ou sua forma de operação, sendo que a necessidade de avaliar a efetividade destas mudanças se faz necessária para que estas IES sirvam de modelo e inspirem outras IES (BRANDLI et al., 2012). De acordo com Araújo, Carniello e Sousa (2012), as Universidades, através dos trabalhos realizados na sociedade em suas áreas de atuação, ensino, pesquisa e extensão, são organizações estratégicas que têm a função social de despertar na comunidade a importância do seu papel na tomada de decisão para as mudanças e transformações necessárias para o Desenvolvimento Sustentável das regiões, nas quais estão inseridas.

Na visão de Tauchem e Brandli (2006), é indispensável que IES comecem a incorporar os princípios e práticas da sustentabilidade, conscientizando, em todos os seus níveis, professores, funcionários e alunos, assim como aplicar decisões fundamentais sobre planejamento, treinamento, operações ou atividades comuns em suas áreas físicas. Ainda a esse respeito, Guerra (2015) relata que a comunidade universitária, que convive no campus interage com os fluxos de matéria e energia, consome bens e serviços naturais e produz tipos diferenciados de resíduos e promovem impactos ambientais de diversas ordens, tal como ocorre nos municípios brasileiros, dependendo do tamanho do campus. Especificamente, sobre eletricidade, Bonnet et al. (2001) salientam que nos grandes campi universitários o uso dela é semelhante ao de cidades de médio porte. Sendo a produção e o uso de energia causadores de degradação ambiental, é papel das IES reduzir o consumo de energia elétrica, como forma de atenuar os danos que elas mesmas causam.

Ourtro fator importante é que as IES, principalmente as grandes consumidoras de energia, são intimamente afetadas por problemas causados pela escassez de recursos não renováveis e pelas alterações climáticas. Além disso, Lo (2013) considera que os custos de energia crescentes tornaram-se um grande impedimento para o crescimento das IES. Estas são razões pelas quais as IES em todo o mundo e, aqui em especial, as UF precisam estar efetivamente engajadas na prática da Conservação de Energia (CE). Altan (2010) relata que 83\% das IES do Reino Unido têm adotado iniciativas para a eficientização do consumo de energia elétrica. Da mesma forma, IES da China também têm demonstrado preocupação com a CE e vêm adotando iniciativas para a promoção da EE e da CE (LO, 2013). Ambos os autores classificam a iniciativas como: Iniciativas Técnicas; e Iniciativas Não Técnicas. Algumas destas iniciativas são apresentadas no Quadro 1. As Iniciativas Técnicas equivalem aos Mecanismos de Base Tecnológica e as Iniciativas Não Técnicas, equivalem aos Mecanismos de Base Comportamental, ambas já mencionadas.

\section{Legislações Pertinentes ao Uso de Energia Elétrica em Universidades Federais brasileiras}

As autoridades brasileiras, também se colocando com um ator que visa a promoção da CE e EE, vêm adotando uma série de políticas públicas, desde a década de 1980, com edições de medidas legais, para a mudança de uma situação atual para uma situação ideal possível relativo ao uso responsável e sustentável de energia elétrica no País. Aqui, entende-se políticas públicas, tais como concebidas por Secchi $(2013$, p. 2) que considera que a política pública como uma diretriz - uma orientação de um policymaker (fazedores de política pública) à atividade ou à passividade de um policytaker (destinatários de uma política pública) - concebida "com o objetivo de enfrentar um problema público".

Segundo o mesmo autor, concordado por Ferreira (2018), para ser uma política pública é necessário que coexistam a intencionalidade pública e a resposta a um problema público. Dessa forma, o conceito de política pública está atrelado à tentativa de tratar ou de resolver um problema entendido como coletivamente relevante, tal como o uso racional de energia elétrica, através de leis, decretos e outros instrumentos legais que disciplinam a intencionalidade proposta. Há de se iniciar pelo Decreto n 99.656, de 26 de outubro de 1990, como sendo a primeira iniciativa do Estado Brasileiro relativa a prática da CE direcionada ao poder público. Este Decreto determinou a criação de uma Comissão Interna de Conservação de Energia (CICE) em cada estabelecimento pertencente a órgão ou entidade da Administração Pública Federal - direta ou indireta, fundações, empresas públicas e sociedades de economia mista - que apresentava con- 
Quadro 1 - Intervenções em Instituições de Ensino do Reino Unido e da China.

\begin{tabular}{|c|c|c|}
\hline Iniciativas & Reino Unido & China \\
\hline Técnicas & $\begin{array}{l}\text { Instalação de sistemas de controle de aquecimento, iluminação e motores. } \\
\text { Instalação de sistemas de medição. } \\
\text { Melhoramento da eficiência dos equipamentos como a substiuição de } \\
\text { caldeiras. } \\
\text { Melhoria no isolamento térmico de prédios. } \\
\text { Uso de sistemas combinados de geração de energia e aquecimento. } \\
\text { Uso de paineis fotovoltaicos. }\end{array}$ & $\begin{array}{l}\text { Uso de lâmpadas com tecnologia } \\
\text { LED (diodo emissor de luz) e } \\
\text { fluorecentes compactas. } \\
\text { Uso de paineis solares para } \\
\text { iluminação de ruas. } \\
\text { Controle de iluminação por } \\
\text { sensores infra-vermelhos } \\
\text { (sensores de presença). }\end{array}$ \\
\hline Não Técnicas & $\begin{array}{l}\text { Modificação de comportamento pelo uso de programas educativos, como } \\
\text { workshops regulares. } \\
\text { Modificação de comportamento pelo uso de programas de recompensa e } \\
\text { punição. } \\
\text { Utilização de ensino a distância para reduzir o consumo de energia no } \\
\text { campus } \\
\text { (neste caso o autor reconhece que embora ocorra a redução no campus, } \\
\text { existe o aumento do consumo nas residências dos estudantes). }\end{array}$ & $\begin{array}{l}\text { Estabelecimento de um grupo } \\
\text { de liderança responsável pelo } \\
\text { planejamento de longo prazo } \\
\text { e ações de CE, bem como o } \\
\text { gerenciamento diário das } \\
\text { operações, incorporação da CE } \\
\text { na avaliação de funcionários e } \\
\text { reconhecimento dos esforços } \\
\text { de CE. } \\
\text { Instalação de medidores de } \\
\text { energia nos dormitórios dos } \\
\text { estudantes e estabelecimento } \\
\text { de cobrança de taxas no caso } \\
\text { de extrapolação do limite de } \\
\text { consumo de energia elétrica. } \\
\text { Política de restrição de uso de } \\
\text { energia em certos horários e de } \\
\text { aparelhos com potência elevada. } \\
\text { Planejamento do calendário } \\
\text { acadêmico de acordo com as } \\
\text { estações do ano de menor } \\
\text { consumo de energia. } \\
\text { Medidas de conscientização } \\
\text { que envolvem campanhas de } \\
\text { divulgação de informações } \\
\text { e realização de seminários e } \\
\text { eventos promovendo a CE. }\end{array}$ \\
\hline
\end{tabular}

Fonte: Elaborado pelos autores (2018), com base em Lo (2013) e Altan (2016).

sumo anual de energia elétrica superior a $600.000 \mathrm{kWh}$, sinalizando uma tentativa de reduzir o desperdício de energia no Setor Público (BRASIL, 1990).

De acordo com Brasil (1990), a CICE ficou responsável pela elaboração, implantação e acompanhamento das metas do Programa de CE e a divulgação dos seus resultados nas dependências de cada estabelecimento. Em 21 de setembro de 1993, foi promulgado o Decreto no 1.716, que criou o Grupo Executivo do Programa Nacional de Racionalização da Produção e do Uso de Energia (GERE). Uma das atribuições do GERE foi acompanhar e orientar o desenvolvimento das atividades das Comissões Internas de Conservação de Energia - CICE (BRASIL, 1993).

O Decreto no 1.927 , de 8 de dezembro de 1993, instituiu o Prêmio Nacional de Conservação e Uso Racional de Energia, a ser conferido para: 1) órgãos e empresas da administração pública; 2) empresas do setor energético;
3) indústrias; 4) empresas comerciais e de serviços; 5) micro e pequenas empresas; 6) edificações; 7) transporte; e 8) reportagens. Essa premiação foi destinada ao reconhecimento das contribuições em prol da conservação e do uso racional da energia no país e conferida anualmente (BRASIL, 1993). Foi instituído, em 01 de julho de 1997, pela ELETROBRÁS/PROCEL, o Programa de EE em Prédios Públicos (Procel EPP), a fim de promover a EE nos prédios públicos, nos níveis federal, estadual e municipal (PROCEL, 2006). Este Programa visava a implementação de medidas de EE e a difusão da informação na Administração Pública, promovendo assim:

Diminuição de gastos dos prédios públicos, através da redução do consumo e da demanda de energia elétrica;

Melhoraria das condições de trabalho, conforto e segurança dos servidores públicos;

Capacitação em EE para administradores e servidores 
de prédios públicos; e

Capacitação laboratorial em EE. (BRASIL, 2011, p.81).

O Procel EPP faz uso das seguintes estratégias: 1) implementação de projetos-piloto para demonstração; 2) substituição de tecnologias obsoletas por eficientes; 3) promoção de plano de capacitação de administradores de prédios públicos em EE; e 4) instrumentos normativos (BRASIL, 2011, p.81). O Decreto no 3330, de 6 de janeiro de 2000, determinava que os órgãos da Administração Pública direta, fundações, empresas e sociedades de economia mista, controladas diretas ou indiretamente pela União, deveriam reduzir em $20 \%$, o consumo de energia elétrica (para fins de iluminação, refrigeração e arquitetura ambiental), até dezembro de 2002 , tendo como base o ano de 1998 (BRASIL, 2000). Este Decreto atribuiu tal responsabilidade aos administradores dos órgãos e entidades, que deveriam adotar as providências pertinentes necessárias à consecução dos objetivos a serem alcançados.

O Decreto no 4.131, de 14 de fevereiro de 2002, também impunha limites de consumo de energia elétrica, baseado no histórico de consumo de anos anteriores, para órgãos da Administração Pública federal, autárquica e fundacional (BRASIL, 2002). Este Decreto buscou inovação ao determinar que os órgãos da Administração Pública federal direta, autárquica e fundacional deveriam diagnosticar o grau de EE dos imóveis sob sua administração. Além disso, na elaboração de projetos de redução do consumo de energia elétrica, assim como, para a aquisição de materiais e equipamentos ou contratação de obras e serviços, deveriam ser adotadas especificações que atendessem aos requisitos inerentes à EE.

Na Portaria 113-MME, de 15 de março de 2002, novamente foram impostas metas de redução de consumo. Neste caso, determinou-se que as autarquias, empresas públicas e sociedades de economia mista vinculadas ao MME, em todo o território nacional, deveriam consumir no máximo o equivalente a $82,5 \%$ do consumo mensal, tendo por referência o mesmo mês do ano 2000, a partir de março de 2002 (BRASIL, 2002). Outra determinação foi a de que as unidades consumidoras deveriam ser cadastradas junto ao PROCEL e que deveriam informar, mensalmente, o consumo verificado em suas instalações (BRASIL, 2002). Esta Portaria, entretanto, não determinou punição aos órgãos públicos, em caso de descumprimento.

Em 2012, foi criado o PLS, entendida como uma ferramenta de planejamento que permite aos órgãos ou entidades estabelecer práticas de sustentabilidade e racionalização de gastos e processos na Administração Pública. O PLS foi criado pelo art. 16, do Decreto no 7.746, de 5 de junho de 2012 (BRASIL, 2012). O PLS foi regulamentado pela Instrução Normativa no 10 , do Ministério do Planejamento, Orçamento e Gestão (MPOG), em 12 de novembro de 2012, que estabeleceu as regras para sua elaboração. Este deverá contemplar sete temas mínimos, entre eles, o tema Energia Elétrica (BRASIL, 2012), objeto desta pesquisa.

A Portaria do MPOG no 23, de 12 de fevereiro de 2015, estabelece boas práticas de gestão e uso de Energia Elétrica e de Água nos órgãos e entidades da Adminis- tração Pública federal direta, autárquica e fundacional. Esta normativa dispõe ainda sobre o monitoramento de consumo desses bens e serviços (BRASIL, 2015). No Anexo I da mesma Portaria, estão elencadas práticas imediatas e permanentes, para promover o uso racional da energia elétrica nos órgãos e entidades da Administração Pública federal direta, autárquica e fundacional. Estas práticas são relacionadas aos usos adequados de aparelhos de ar condicionado, sistemas de iluminação, computadores, refrigeradores, aquecedores, elevadores e bebedouros (BRASIL, 2015).

\section{Metodologia}

\section{Caracterização}

Este trabalho faz parte de uma investigação científica maior denominada "Compromisso e Implantação de Práticas Sustentáveis em Instituições de Ensino Superior", financiada pela Fundação de Apoio ao Desenvolvimento do Ensino, Ciência e Tecnologia do Estado de Mato Grosso do Sul (Fundect). Ela está vinculada ao Grupo de Pesquisa "Dinâmica Evolutiva das Organizações Humanas", registrado no Diretório de Pesquisa do Conselho Nacional de Desenvolvimento Científico e Tecnológico (CNPq), um órgão oficial integrante do Ministério da Educação (MEC). Dentro daquela investigação maior, algumas pesquisas já foram realizadas com os demais temas mínimos, exigidos na IN10/2012, a exemplo de Franco et al (2017), Nogueira (2018), Nogueira et al (2018a), Rissato (2018) Rissato et al (2018a), Campos (2018) e Kihara (2018), Kihara et al (2019). Para a construção e delineamento desta pesquisa, foi consultado o Code of Conduct and Best Practice Guidelines for Journal Editors (COPE, 2011). Igualmente, acatou as instruções descritas ao longo do Manual Boas Práticas da Publicação Científica, defendidas pela ANPAD (2018).

Esta pesquisa é considerada como um estudo descritivo e exploratório. Triviños (1987) salienta que no campo da educação, a maioria dos estudos que se realizam é de natureza descritiva. Para o autor, o foco essencial desses estudos reside no desejo de conhecer a amostra, seus traços característicos, seus problemas e descrever com exatidão os fatos e fenômenos de uma realidade. De acordo com Gil (2008), as pesquisas exploratórias podem ser desenvolvidas objetivando proporcionar visão geral e aproximativa acerca de determinado fato. Além disso, também podem desenvolver, esclarecer e modificar conceitos e ideias. As pesquisas exploratórias envolvem levantamento bibliográfico e documental, entrevistas não padronizadas e Estudos de Caso. Entre os tipos de pesquisa, estas são as que apresentam menor rigidez no planejamento (MARCONI; LAKATOS, 2003),

Prodanov e Freitas (2013) esclarecem que é imprescindível correlacionar a pesquisa com o universo teórico. Para os autores, isto se faz por meio da revisão de literatura, e possibilita optar por um modelo que sirva 
de embasamento à interpretação do significado dos dados e fatos colhidos ou levantados. Sob este enfoque, nesta pesquisa, a revisão da literatura teve como fonte de dados sítios oficiais do Governo Federal brasileiro, sítios oficiais de organizações internacionais, artigos científicos, teses, dissertações e legislações. Optou-se também por uma pesquisa documental, uma vez que foram analisados os PLS, os PA e os respectivos RA das Universidades Federais brasileiras.

Para que os objetivos desta pesquisa pudessem ser atingidos, optou-se por uma abordagem predominantemente qualitativa. Esse tipo de pesquisa, em geral, pode ter como objetivo oferecer uma descrição ou avaliação. A pesquisa qualitativa não consiste em um método padronizado único (FLICK, 2013). Mansano (2013, p.119) salienta que os métodos qualitativos vêm sendo cada vez mais utilizados como estratégia de investigação, com o objetivo de acompanhar as transformações que acontecem nas organizações. Salienta, ainda, que "tais pesquisas ocupam-se de problematizar os acontecimentos em sua emergência histórica, atentando para sua singularidade e para o delineamento de novas realidades sociais".

\section{Etapas da Pesquisa}

Esta pesquisa foi executada em quatro etapas: 1) Revisão da literatura e levantamento documental sobre leis e normatizações mais relevantes sobre o tema energia elétrica; 2 ) Com base na pesquisa documental combinada com um levantamento bibliométrico, criação de forma dedutiva de categorias que possibilitem a análise dos PA e dos respectivos RA do PLS das 63 UF; 3) Coleta dos PLS e suas atualizações (os PA subsequentes ao PLS), e também dos RA das 63 UF; e 4) Classificação e análise dos PA e dos RA do PLS das UF que disponibilizaram os documentos.

A primeira etapa da pesquisa consistiu na busca em meio eletrônico (Portal de Periódicos CAPES e Google Acadêmico), por publicações científicas que possibilitassem identificar e conceituar quais os temas eram relevantes no que tange ao uso de energia elétrica nas IES. Neste caso, as questões relacionadas à CE e EE eram as que mais se aproximavam dos objetivos do PLS, ou seja, aquelas que estabeleciam práticas de sustentabilidade e racionalização dos gastos e processos na Administração Pública. As palavras-chaves utilizadas foram: eficiência energética e universidade; eficiência energética e faculdade; eficiência energética e ensino superior; energia elétrica e universidade; energia elétrica e faculdade; e energia elétrica e ensino superior. A busca foi realizada entre janeiro e maio de 2008.

Após esse estudo preliminar, ainda na primeira etapa da pesquisa, foi feito o levantamento da legislação relacionada ao tema mínimo Energia Elétrica, assim como as normas, acordos e parcerias nacionais e internacionais, sobre este tema, dos quais o Brasil faz parte. A segunda etapa consistiu em, com o apoio do material pesquisado, criar categorias de classificação que pudessem ser usadas para analisar e classificar as ações empreendidas pelas UF no contexto de seus PLS. A criação das categorias teve como base os mecanismos de implementação. A terceira etapa consistiu na coleta dos PA e RA dos PLS das 63 UF. A busca ocorreu nos sites oficiais das instituições. Para as UF que não disponibilizam os documentos em seus sites, foi feita uma solicitação pelos canais de comunicação disponíveis. $\mathrm{Na}$ quarta etapa, as ações pertinentes ao tema mínimo energia elétrica foram classificadas com base nas categorias criadas na segunda etapa. Após a classificação, procedeu-se análise dos dados obtidos.

\section{Procedimentos de Coleta e Tratamento de Dados}

Para Gil (2008), as pesquisas descritivas têm como objetivo primordial a descrição das características de determinada população, ou estabelecimento de relações entre variáveis. Nesta pesquisa a população é composta pelas 63 UF, distribuídas em cinco regiões. A coleta de dados ocorreu nos sítios institucionais das UF, entre 05 de maio de 2018 e 25 de junho de 2018.

Nesta pesquisa, optou-se por utilizar dados provenientes de documentos. Segundo Gil (2008), para fins de pesquisa científica são considerados documentos não apenas os escritos utilizados para esclarecer determinada coisa, mas qualquer objeto que possa contribuir para a investigação de determinado fato ou fenômeno. Este autor salienta que a pesquisa documental faz uso de materiais que não recebem ainda um tratamento analítico, ou que ainda podem ser reelaborados de acordo com os objetivos da pesquisa. Assim sendo, foram buscados os PLS, assim como os PA, os respectivos RA e quaisquer outros documentos relacionados ao PLS que estivessem disponíveis.

Desta forma, os dados de pesquisa são caracterizados como secundários (GIL, 2008), pois foram coletados através de um Censo, com base nas divulgações dos PLS das 63 UF, os quais são compostos por diretrizes e um PA. Também fazem parte dos dados os respectivos RA que avaliam as implementações dos PA. Estes dados foram coletados nos sítios oficiais das $63 \mathrm{UF}$, sendo que para aquelas que não disponibilizaram estes documentos em seus sítios, foram feitas solicitações por e-mail. Estes são dados tipificados, portanto, como secundários, uma vez que não foram produzidos para esta pesquisa (FLICK, 2013; PRODANOV; FREITAS, 2013).

Os dados coletados foram tratados por meio de análise de conteúdo, seguindo as orientações de Bardin(2004), que enfatiza o uso de categorias para análise. Este tipo de análise é um processo auto-organizado de produção de novas compreensões em relação aos fenômenos que examina, através do estabelecimento de relações entre os documentos analisados e as categorias elaboradas de forma dedutiva (MORAES, 2003). O Quadro 2 apresenta as categorias para a análise de dados e as ações descritas nas regulamentações e publicações que são identificadas nos PLS das UF.

Após a busca, constatou-se que $54 \%$ das UF segu- 
Quadro 2 - Categorias para a análise das ações de eficiência energética.

\begin{tabular}{|c|c|c|c|c|}
\hline & \multicolumn{4}{|c|}{ Regulamentações e orientações } \\
\hline Mecanismos de base tecnológica & $\begin{array}{c}\text { ANEEL - Resolução Normativa no } \\
414 / 2010\end{array}$ & $\begin{array}{c}\text { Portaria do MPOG no } \\
23 / 2015\end{array}$ & $\begin{array}{c}\text { In MPOG- } \\
10 / 12\end{array}$ & A3p \\
\hline $\begin{array}{l}\text { Mecanismos de base } \\
\text { comportamental }\end{array}$ & & $\begin{array}{c}\text { Portaria do MPOG no } \\
\text { 23/2015 }\end{array}$ & $\begin{array}{l}\text { In MPOG- } \\
10 / 12\end{array}$ & A3p \\
\hline Medidas administrativas & $\begin{array}{c}\text { ANEEL - Resolução Normativa no } \\
414 / 2010\end{array}$ & $\begin{array}{c}\text { Portaria do MPOG no } \\
\text { 23/2015 }\end{array}$ & $\begin{array}{l}\text { In MPOG- } \\
10 / 12\end{array}$ & \\
\hline
\end{tabular}

Fonte: elaborado pelos autores, a partir da Resolução Normativa da ANEEL $\mathrm{n}^{\circ}$ 414, de 9 de setembro de 2010, (BRASIL, ANEEL, 2010), da Portaria do MPOG no 23, de 12 de fevereiro de 2015. (BRASIL, MPOG, 2010), da Instrução Normativa do MPOG no 10 , de 12 de novembro de 2012. (BRASIL, MPOG, 2012), da A3P (BRASIL, 2009),

NOGUEIRA (2007), ALTAN (2010). LO (2013) e Krause et al. (2002).

ramente implantaram o PLS, ao passo que $46 \%$ das UF não disponibilizaram seus PLS. Embora não seja possível determinar se estas UF tinham ou não PLS, ficou evidente que elas não cumprem as determinações dos art. 12 e 13 da Instrução Normativa no 10/2012 do MPOG, no que tange a publicação de tais documentos em seus sites. A Tabela 1 traz uma melhor visualização da disponibilização dos PLS, por região do País.

Tal como pode ser observado na Tabela 1, a região Centro-Oeste contém 5 UF, sendo a região com o menor número de UF, se destaca com o maior índice de disponibilização do PLS, $80 \%$ no total. A região Sul $11 \mathrm{UF}$, dentre as quais $73 \%$ já disponibilizaram o PLS. As regiões Norte e Nordeste, com 18 UF respectivamente, apresentaram um índice de disponibilização do PLS de $50 \%$. A região Sudeste, contém o maior número de UF, 19 no total, apresentou o menor índice de disponibilização do PLS. A respeito dos dados relacionados aos RA, entre as $34 \mathrm{UF}$ que disponibilizaram o PLS, foram encontradas 15 , que publicaram tais documentos.

Tabela 1 - Porcentagem de Universidades Federais brasileiras que disponibilizaram seus PLS

\begin{tabular}{l|cccc}
\hline Região & N $^{\circ}$ de UF & UF com PLS & \% por Região \\
\hline Centro-Oeste & 5 & 4 & 80 \\
Nordeste & 18 & 9 & 50 \\
Norte & 10 & 5 & 50 \\
Sudeste & 19 & 9 & 47 \\
Sul & 11 & 8 & 73 \\
Total & 63 & 34 & 54\% das UF \\
\hline
\end{tabular}

Fonte: Autores da pesquisa (2018)

A Tabela 2 apresenta as UF que disponibilizaram os respectivos RA, organizadas por região. Nela, observa-se que a região Centro-Oeste apresentou o maior número de UF com RA publicados, chegando a $100 \%$. Em seguida, na região Sul $50 \%$ das UF publicaram seus respectivos RA. Todas as outras regiões ficaram abaixo de $50 \%$.
Tabela 2 - Porcentagem de UF que disponibilizaram RA, organizadas por região

\begin{tabular}{lccc}
\hline Região & No de UF com PLS $^{\circ}$ & RA & \% por Região \\
\hline Centro-Oeste & 4 & 4 & 100 \\
Nordeste & 9 & 4 & 44 \\
Norte & 5 & 2 & 40 \\
Sudeste & 8 & 3 & $37 \%$ \\
Sul & 8 & 4 & $50 \%$ \\
Total & 34 & 15 & $44 \%$ das IES \\
Fonte: Autores da pesquisa (2018) & &
\end{tabular}

\section{Análise e discussão dos resultados}

\section{Análise das Vigências dos Planos de Ações das Universidades Federais brasileiras}

Primeiramente, foram analisadas a vigência e as atualizações dos PA que compõem os PLS. A existência de um PLS atualizado ou de um PA vigente é um indicativo de que a UF está desenvolvendo práticas de sustentabilidade e racionalização de gastos de forma continuada. Todas as UF deveriam ter ações planejadas de forma contínua para os temas mínimos do PLS. Entretanto, os dados apresentados demonstram que mesmo as UF que já implantaram o PLS, em sua maioria não tinham ações planejadas.

Não foi previsto na legislação nenhum prazo de validade ou rol de ações que completadas, venham a extinguir o PLS. Neste sentido, o PLS é uma ferramenta que uma vez implantada, deve continuar atuante para promover práticas de sustentabilidade e racionalização de gastos. O Gráfico 1 apresenta o percentual UF, dentre as 63 pesquisadas, que apresentaram um PA vigente.

O prazo inicial para elaboração dos PLS foi legalmente agendado para 14 de maio de 2013. Após esse prazo, todos os órgãos e entidades da Administração Pública Federal direta, autárquica, fundacional e as empresas estatais dependentes deveriam ter seus PLS implantados e um PA válido para os temas mínimos. Em maio de 2018, quando encerrou a coleta de dados desta pesquisa, a maior parte das UF não tinha um PA vigente. 
Gráfico 1 - Total Universidades Federais com Planos de Ações vigentes

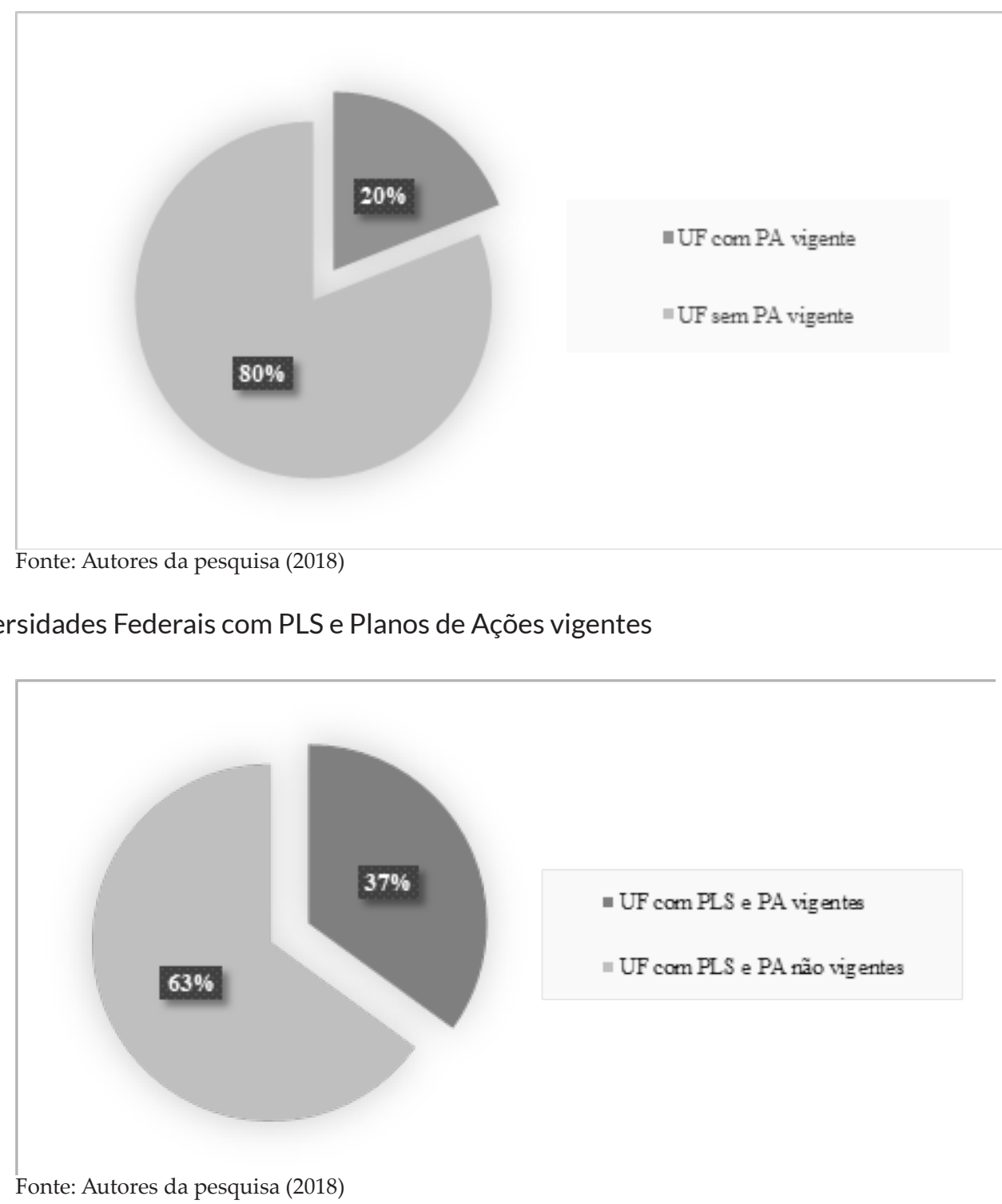

Gráfico 2 - Universidades Federais com PLS e Planos de Ações vigentes

Fonte: Autores da pesquisa (2018)

No Gráfico 2, verifica-se que entre as 34 UF que já implantaram e disponibilizaram o PLS, aproximadamente $80 \%$ não tinham ações futuras planejadas. Este dado sugere a falta de continuidade das ações, ou seja, mesmo que a UF outrora tenham desenvolvido ações para o tema mínimo energia elétrica, ela não tinha dado continuidade ao trabalho.

\section{Análise dos Planos de Ações das Universidades Federais brasileiras}

A análise dos PA das 35 UF, que disponibilizaram seus PLS revelou que 32 delas planejaram, pelo menos uma ação em cada uma das categorias, abrangendo assim: Mecanismos de Base Tecnológica; Mecanismos de Base Comportamental; e Medidas Administrativas. Verificou-se que 3 UF não contemplaram todas as categorias. O Quadro 3 traz as práticas relacionadas à Energia Elétrica, dentro das categorias propostas para essa pesquisa.
A categoria Medidas Administrativas teve 100\% de adesão, ou seja, todas as UF que elaboraram o PLS planejaram alguma ação dentro desta categoria. Ao todo, foram encontradas 96 proposições nos PA, distribuídas em um conjunto de 13 ações.

De forma complementar, a Tabela 3 apresenta as ações mais propostas pelas UF e o seu percentual em relação ao total de ações propostas. Nela, vê-se que apenas a número 2 podem demandar algum investimento financeiro, caso haja a opção por contratar uma empresa especializada para a realização de um diagnóstico energético. Em se tratando de UF, também é possível que esse diagnóstico seja realizado pelos engenheiros que compõem o corpo técnico da instituição. Em UF, nas quais possam existir cursos da área de engenharia, também é possível vincular a execução do diagnóstico energético com projetos acadêmicos, aproveitando os corpos docente e discente.

As outras ações não demandam investimento financeiro, apenas recursos humanos. As alterações 
Quadro 3 - Práticas Relacionadas à Energia Elétrica nos PA dos PLS das Universidades Federais brasileiras

\begin{tabular}{|c|c|c|c|c|}
\hline \multirow[b]{2}{*}{ UF } & \multicolumn{4}{|c|}{ O PLS apresentado pelas UF atende às categorias de Energia Elétrica } \\
\hline & $\begin{array}{c}\text { Mecanismos de Base } \\
\text { Tecnológica }\end{array}$ & $\begin{array}{l}\text { Mecanismos de Base Com- } \\
\text { portamental }\end{array}$ & $\begin{array}{c}\text { Medidas Administra- } \\
\text { tivas }\end{array}$ & $\begin{array}{l}\text { \% de categorias no } \\
\text { PLS por UF }\end{array}$ \\
\hline UFABC & $x$ & $x$ & $x$ & $100 \%$ \\
\hline UFBA & $x$ & & $x$ & $67 \%$ \\
\hline UFC & $x$ & $x$ & $x$ & $100 \%$ \\
\hline UFCSPA & $x$ & $x$ & $x$ & $100 \%$ \\
\hline UFRPE & $x$ & $x$ & $x$ & $100 \%$ \\
\hline UFERSA & $x$ & $x$ & $x$ & $100 \%$ \\
\hline UFF & $x$ & $x$ & $x$ & $100 \%$ \\
\hline UFFS & $x$ & $x$ & $x$ & $100 \%$ \\
\hline UFG & $x$ & $x$ & $x$ & $100 \%$ \\
\hline UFGD & $x$ & $x$ & $x$ & $100 \%$ \\
\hline UFMA & $x$ & $x$ & $x$ & $100 \%$ \\
\hline UFMS & $x$ & $x$ & $x$ & $100 \%$ \\
\hline UFMT & & & $x$ & $33 \%$ \\
\hline UFOPA & $x$ & $x$ & $x$ & $100 \%$ \\
\hline UFPA & $x$ & $x$ & $x$ & $100 \%$ \\
\hline UFPB & $x$ & $x$ & $x$ & $100 \%$ \\
\hline UFPR & $x$ & $x$ & $x$ & $100 \%$ \\
\hline UFRA & $x$ & $x$ & $x$ & $100 \%$ \\
\hline UFRB & $x$ & $x$ & $x$ & $100 \%$ \\
\hline UFRGS & $x$ & $x$ & $x$ & $100 \%$ \\
\hline UFRR & $x$ & $x$ & $x$ & $100 \%$ \\
\hline UFS & $x$ & $x$ & $x$ & $100 \%$ \\
\hline UFSC & $x$ & $x$ & $x$ & $100 \%$ \\
\hline UFSJ & $x$ & $x$ & $x$ & $100 \%$ \\
\hline UFSM & $x$ & $x$ & $x$ & $100 \%$ \\
\hline UFT & $x$ & $x$ & $x$ & $100 \%$ \\
\hline UFTM & $x$ & $x$ & $x$ & $100 \%$ \\
\hline UFVJM & $x$ & $x$ & $x$ & $100 \%$ \\
\hline UNIFAL & $x$ & $x$ & $x$ & $100 \%$ \\
\hline UNIFEI & $x$ & $x$ & $x$ & $100 \%$ \\
\hline UNIFESP & $x$ & $x$ & $x$ & $100 \%$ \\
\hline UNIPAMPA & $x$ & $x$ & $x$ & $100 \%$ \\
\hline UNIRIO & $x$ & $x$ & $x$ & $100 \%$ \\
\hline UNIVASF & $x$ & $x$ & $x$ & $100 \%$ \\
\hline UTFPR & $x$ & & $x$ & $67 \%$ \\
\hline Total/Categoria & $97 \%$ & $91 \%$ & $100 \%$ & \\
\hline
\end{tabular}

Fonte: Autores da pesquisa (2018) 
Tabela 3 - Ações Propostas na Categoria Medidas Administrativas

\begin{tabular}{|c|c|c|}
\hline Conjunto de ações & Proposições & Percentual \\
\hline 1. Alterações das políticas de contratações e aquisições. & 20 & $21,5 \%$ \\
\hline 2. Fazer o diagnóstico da situação das instalações elétricas e do uso de energia. & 20 & $21,5 \%$ \\
\hline $\begin{array}{l}\text { 3. Monitorar o consumo de energia elétrica periodicamente e realizar projeções de } \\
\text { crescimento futuro deste consumo. }\end{array}$ & 18 & $19,3 \%$ \\
\hline 4. Revisar e readequar contratos de fornecimento. & 13 & $14 \%$ \\
\hline 5. Estabelecer rotinas de manutenção preventiva e corretiva. & 8 & $8,7 \%$ \\
\hline Outras ações & 14 & $15 \%$ \\
\hline Total & 93 & $100 \%$ \\
\hline
\end{tabular}

Fonte: Autores da pesquisa (2018)

das políticas de contratações e aquisições referem-se a ações que estabelecem critérios de EE na elaboração das licitações. Este tipo de ação já foi tratado no Decreto 7.746 de 5 de junho de 2012, que determinou que a aquisição de bens, bem como na contratação de serviços e obras, a administração pública federal direta, autárquica e fundacional e as empresas estatais dependentes deveriam adotar critérios e práticas sustentáveis, dentre elas a maior eficiência na utilização de recursos naturais como água e energia.

De forma similar, a Portaria ${ }^{\circ} 23$, de 12 de fevereiro de 2015 do MPOG, determina que nas aquisições ou locações de máquinas e aparelhos consumidores de energia, que estejam regulamentados no Programa Brasileiro de Etiquetagem (PBE), deve-se exigir, nos instrumentos convocatórios, que os modelos dos bens fornecidos possuam ENCE. A terceira, a quarta e a quinta ações, embora sejam de grande importância para $\mathrm{CE}$, não representaram um avanço significativo nas políticas de sustentabilidade das UF, pois foram ações ordinárias, inerentes de qualquer instalação elétrica de médio e grande porte. A categoria Mecanismos de Base Tecnológica teve $97 \%$ de adesão, sendo que, apenas a UFMT não propôs nenhuma ação nesta categoria. Esta foi a categoria com o maior número de ações propostas, ao todo foram encontradas 129 proposições nos PA, distribuídas em um conjunto de
18 ações. A Tabela 4 apresenta as ações mais propostas pelas UF e o seu percentual em relação ao total de ações propostas.

O estudo de viabilidade de uso de fontes alternativas de energia não envolve investimentos financeiros. Esta ação, não necessariamente, pode resultar na instalação de um sistema de geração alternativa de energia, uma vez que o estudo pode concluir que este não é viável técnica ou economicamente. Ainda que utilização de fontes de energia alternativas não trate de como a energia é utilizada, mas sim produzida, e que não seja possível promover uma redução do consumo de energia elétrica através dessa ação, ela é considerada uma medida de promoção da EE. Todas as outras ações acima mencionadas envolvem investimento financeiro. Por isso, em geral, demandam por parte de administrador um estudo de viabilidade econômica, em que o retorno do capital investido muitas vezes pesa na decisão pela implementação ou não das ações.

A categoria Mecanismos de Base Comportamental teve $91 \%$ de adesão. A UFBA, a UFMT, e a UTFPR não propuseram nenhuma ação nesta categoria. Esta foi a categoria com o menor número de ações propostas, ao todo foram encontradas quarenta e seis proposições nos PA, distribuídas em um conjunto de onze ações. A Tabela 5 apresenta as ações mais propostas pelas UF e o seu percentual em relação ao total de ações propostas.

Tabela 4 - Ações Propostas na Categorria Mecanismos de Base Tecnológica

\begin{tabular}{|c|c|c|}
\hline Conjunto de ações & Proposições & Percentual \\
\hline $\begin{array}{l}\text { 1. Promover estudos que analisem a viabilidade do uso de fontes alternativas de energia } \\
\text { (solar, termoelétrica, eólica). }\end{array}$ & 19 & $14,7 \%$ \\
\hline 2. Instalar medidores de energia para individualização de medição. & 17 & $13,2 \%$ \\
\hline 3. Instalar sensores e temporizadores para automatização da iluminação. & 15 & $11,6 \%$ \\
\hline 4. Mapear e substituir aparelhos que causam maior consumo de energia. & 14 & $10,9 \%$ \\
\hline 5. Utilizar lâmpadas econômicas nas salas de aula e da administração. & 12 & $9,3 \%$ \\
\hline Outras ações & 52 & $40,3 \%$ \\
\hline Total & 129 & $100 \%$ \\
\hline
\end{tabular}

Fonte: Autores da pesquisa (2018) 
Tabela 5 - Ações Propostas na Categoria Mecanismos de Base Comportamental

\begin{tabular}{|c|c|c|}
\hline Conjunto de ações & Proposições & Percentual \\
\hline 1. Realizar campanhas para conscientização do uso de energia elétrica. & 23 & $50,0 \%$ \\
\hline $\begin{array}{l}\text { 2. Dar preferência ao sistema de luz natural, abrindo as janelas, cortinas e dispondo o } \\
\text { mobiliário de forma a aproveitar a luz solar. }\end{array}$ & 6 & $13,0 \%$ \\
\hline 3. Desligar luzes e equipamentos quando estes não estiverem em uso. & 4 & $8,7 \%$ \\
\hline 4. Realizar treinamento dos servidores. & 4 & $8,7 \%$ \\
\hline $\begin{array}{l}\text { 5. Utilizar o ar condicionado de forma consciente ajustando o controle de temperatura para } \\
\text { um valor que mantenha o ambiente confortável termicamente. }\end{array}$ & 3 & $6,6 \%$ \\
\hline Outras ações & 6 & $13,0 \%$ \\
\hline Total & 46 & $100 \%$ \\
\hline
\end{tabular}

A realização de campanha de conscientização é um ponto chave para qualquer Programa de EE, uma vez que o consumo e a CE estão diretamente ligados ao comportamento dos usuários. Dentre todas, esta é a ação com maior incidência nos PA da UF. Embora a grande maioria dos PA das UF tenha feito menção à utilização de campanhas de conscientização, não foi encontrado em nenhum PLS maiores informações sobre como elas são realizadas, quais as estratégias usadas, qual a periodicidade, qual seu público alvo ou qualquer outro detalhamento.

As ações 2, 3 e 5 não têm eficácia por si só, uma vez que dependem de outros mecanismos que lhes deem aplicabilidade, como campanhas de conscientização, fiscalização. Estas ações também são comtempladas pela Portaria ${ }^{\circ} 23$, de 12 de fevereiro de 2015 do MPOG, que estabeleceu as boas práticas de gestão e uso de Energia Elétrica nos órgãos e entidades da Administração Pública Federal direta, autárquica e fundacional.

\section{Análise dos Relatórios de Acompanhamento das Universidades Federais brasileiras}

As ações efetivadas (total ou parcialmente), segundo os RA, são apresentadas na Tabela 6 , que assinala o percentual do Índice de Comprometimento com as Metas Definidas nos Planos de Ações (ICMD). Para a obtenção dos Índices foram adotados os seguintes valores:

- $\varnothing$ (vazio) - Não houve menção desta Categoria no RA;

- 1 (um) - Meta totalmente atingida ou contínua;

- 0,5 (meio) - Meta parcialmente atingida ou em execução;

- 0 (zero) - Meta não atingida.

A porcentagem de ICMD de cada UF foi calculada a partir da soma dos valores totais e/ou parciais, das metas alcançadas dentro de cada Categoria, dividido pelo número de propostas definidas no PA. Assim, o ICMD de uma UF que propôs ações contemplando 3 Categorias e concretizou apenas uma foi calculado "ICMD = (Categoria $1+$ Categoria $2+$ Categoria 3$) / 3 "$.

A análise dos RA demonstrou que foi na categoria Medidas Administrativas que foram encontrados os maiores índices de atingimento de metas, com um ICMD de 55\%. A categoria Mecanismos de Base Tecnológica, que é onde foi encontrado o maior número de tipos de ações e de proposições de ações, ficou em segundo lugar com ICMD de $47 \%$. A categoria Mecanismos de Base Comportamental, que teve o menor número de tipos de ações, assim como o menor número de ações propostas pelas UF, também teve o menor ICMD (33\%), o que significa a menor taxa de sucesso de implementações das ações.

Nos RA do PLS analisados para a elaboração da Tabela 6, verificou-se que a UFFS, a UFPB e a UFTPR tiveram o maior Índice de Comprometimento com as Metas Definidas nos Planos de Ações (100\% do ICMD). Estas UF implementaram com sucesso, pelo menos uma ação em cada uma das categorias. A UNIFESP obteve o segundo ICMD mais alto (83\%), considerando que ela contemplou com sucesso as categorias Mecanismos de Base Comportamental e Medidas Administrativas, e parcialmente a categoria Mecanismos de Base Tecnológica. Com ICMD de $66 \%$, UFABC, UFERSA, UFG, UFMS, UFSC e UNIVASF atingiram a meta, em pelo menos uma ação. A UFTM atingiu parcialmente as metas das categorias Medidas Administrativas e Mecanismos de Base Tecnológica.

A UFGD, a UFSM e a UNIFAL tiveram ICMD igual $0 \%$. Entretanto, isso se deve ao fato de seus RA não apresentarem dados a respeito das ações propostas para o tema mínimo energia elétrica. Os dados apresentados, nos RA da UFRA, da UFRB e da UFRR, demonstraram que nenhuma ação foi implementada, com sucesso, em nenhuma das categorias, determinando um ICMD também igual a $0 \%$. 
Tabela 6 - Índice de Comprometimento com as Metas Definidas no Plano de Ação

\begin{tabular}{l|c|c|c|c}
\hline \multirow{2}{*}{ Relatório } & \multicolumn{3}{|c|}{ Categoria } & ICMD \\
\cline { 2 - 4 } & $\begin{array}{c}\text { Mecanismos de Base } \\
\text { Tecnológica }\end{array}$ & $\begin{array}{c}\text { Mecanismos de Base } \\
\text { Comportamental }\end{array}$ & $\begin{array}{c}\text { Medidas } \\
\text { Administrativas }\end{array}$ & \\
\hline 1. UFABC & 1 & 0,5 & 0,5 & $66 \%$ \\
2. UFERSA & 1 & $\varnothing$ & 1 & $66 \%$ \\
3. UFFS & 1 & 1 & 1 & $100 \%$ \\
4. UFG & 0,5 & 0,5 & 1 & $66 \%$ \\
5. UFGD & $\varnothing$ & $\varnothing$ & $\varnothing$ & $0 \%$ \\
6. UFMS & 1 & 0 & 1 & $66 \%$ \\
7. UFMT & $\varnothing$ & $\varnothing$ & $\varnothing$ & $0 \%$ \\
8. UFPB & 1 & 1 & 1 & $100 \%$ \\
9. UFRA & 0 & 0 & 0 & $0 \%$ \\
10. UFRB & 0 & 0 & 0 & $0 \%$ \\
11. UFRR & 0 & 0 & 0 & $0 \%$ \\
12. UFSC & 1 & 0 & 1 & $66 \%$ \\
13. UFSM & $\varnothing$ & $\varnothing$ & $\varnothing$ & $0 \%$ \\
14. UFTM & 0,5 & 0 & 0,5 & $33 \%$ \\
15. UNIFAL & $\varnothing$ & $\varnothing$ & $\varnothing$ & $0 \%$ \\
16. UNIFESP & 0,5 & 1 & 1 & $83 \%$ \\
17. UNIVASF & 0 & 1 & 1 & $66 \%$ \\
18. UTFPR & 1 & 1 & 1 & $100 \%$ \\
Total/Categorias & $47 \%$ & $33 \%$ & $55 \%$ & \\
\hline
\end{tabular}

\section{Considerações finais}

A crescente preocupação com o meio ambiente e a busca por sustentabilidade fez com que a conservação dos recursos naturais e a gestão do meio ambiente ganhassem destaque nas políticas públicas. Diante disto, as autoridades brasileiras passaram a editar medidas para promover a sustentabilidade nos órgãos e entidades públicas, entre elas a criação do PLS. Entende-se que o PLS não é apenas um instrumento que estabelece práticas sustentáveis nas rotinas da Administração Pública. Trata-se de uma resposta aos anseios da sociedade, que cada vez mais se preocupa com o futuro. Sua implementação é obrigatória para todos os entes da Administração Pública Federal direta e indireta, incluindo autarquias, fundações e empresas estatais, universo no qual as UF brasileiras se incluem.

Conforme o estabelecido na Instrução Normativa no 10/2012, do Ministério do Planejamento, Desenvolvimento e Gestão, os PLS devem abranger os temas mínimos Material de Consumo, Energia Elétrica, Água e Esgoto, Coleta Seletiva, Compras e Contratações Sustentáveis, Deslocamento de Pessoal, e Qualidade de Vida no Ambiente de Trabalho. Por conta da metodologia adotada para esta pesquisa, pode-se considerar que menos da metade das UF não tem cumprido a referida norma, quer seja deixando de implementar o PLS, quer seja imple- mentando e deixando de publicar PA atualizados e RA.

Com relação às UF que implementaram o PLS, os PA e seus respectivos RA publicados, constatou-se que, apesar do grande número ações propostas e da elevada taxa de abrangência das categorias, a concretização das ações ficou muito abaixo do planejado, expressa por ICMDs abaixo de $33 \%$ e $47 \%$ para as categorias Mecanismos de Base Comportamental e Mecanismos de Base Tecnológica, respectivamente. A categoria Medidas Administrativas obteve um ICMD de 55\%.

Diante do exposto, há de se considerar que a EE deve ser tratada nas UF com um grau de comprometimento adequado, especialmente porque tornou-se uma especialidade que envolve múltiplas áreas, como as Engenharias Elétrica, Mecânica, Ambiental e a Arquitetura. Muitas UF têm cursos em todas essas áreas do conhecimento, o que possibilita a criação de uma equipe interdisciplinar para ajudar na elaboração dos PA, bem como na avaliação dos RA e na proposição de medidas mais mitigadoras.

Além disso, todo o processo de adequação exige o envolvimento de Stakeholders, especificamente daqueles com poder para direcionar recursos humanos e financeiros, necessários às implementações da EE e da CE. Essa falta de comprometimento ficou evidente, nesta pesquisa, pelo baixo ICMD verificado. Mesmo ações que demandam poucos recursos financeiros e humanos, como 
é o caso da maioria das ações das categorias Mecanismos de Base Comportamental e Medidas Administrativas, foram pouco implementadas. Melhorar o uso da energia consumida nos campi das UF vai além da obtenção dos resultados financeiros decorrentes da CE. Tal medida significa ajudar na conservação de recursos naturais e na redução de danos ambientais. Promover a EE pode também ajudar as UF a corresponder aos anseios sociais e governamentais no tocante à sustentabilidade.

Para pesquisas futuras, sugere-se que haja a continuidade desta pesquisa em outras Instituições de Ensino Superior, a exemplo dos Institutos Federais, que também guardam a missão social de desenvolver pesquisas e formar alunos cidadãos responsáveis pelo uso racional dos recursos naturais e, aqui, em especial, ao objeto desta pesquisa que foi a energia elétrica. Por fim, deixa-se no ar a probabilidade de se ter um número maior, ou quiçá, a totalidade das Universidades Federais brasileiras terem atendidos ao que a IN/10/2012 trouxe em seus cláusulas, se nela também houvesse instruções de punições ou sanções para os órgãos públicos não cumpridores desta normatização.

\section{Referências}

ALTAN, H. Energy efficiency interventions in UK higher education institutions. Energy Policy. [Internet]. 2016[cited 2018 apr 12];38(12):7722-7731. Avaliable from: http:// eprints.whiterose.ac.uk/42 780.

ARAUJO, E.A.S.; CARNIELLO, M.F.; SOUSA, M.G.B. O Papel das Instituições de Ensino Superior. Revista Cereus. [Internet]. 2012[cited 2017 apr 12]; 4(3). Avaliable from: http://www.inicepg.univap.br/cd/INIC_2011/anais/ arquivos/0088_0857_01.pdf

ASSOCIAÇÃO NACIONAL DE PÓS-GRADUAÇÃO E PESQUISA EM ADMINISTRAÇÃO (ANPAD). Boas Práticas da Publicação Científica: um manual para autores, revisores, editores e integrantes de Corpos Editoriais. [Internet]. 2010. [cited, 2018 jun 18]. Avaliable fron: https://www.mackenzie.br/fileadmin/ARQUIVOS/ Public/top/midias_noticias/editora/old/Editora/ Revista_ Administracao/Boas_Praticas.pdf_

BARDIN, Lawrence. Análise do conteúdo. 3. ed. Edições 70, Lda, Lisboa, 2004.

BRANDLI, L.L.; FRANDOLOSO, M.A.L.;VIEIRA, L.C.; PEREIRA, L.A. Avaliação da presença da sustentabilidade ambiental no ensino dos cursos de graduação da Universidade de Passo Fundo. Avaliação. [Internet]. 2012[cited 2017 apr 12]; 17(2):433-454. Avaliable from: http://www.scielo.br/scielo.php?script=sci_ arttext\&pid=S1414-40772012000200008\&lng=en\&nrm=iso
BONNET, J. et al. Analysis of electricity and water enduses in university campuses: case-study of the University of Bordeaux in the framework of the Ecocampus European Collaboration. Journal of Cleaner Production. [Internet]. 2001[cited 2017 apr 12]; 10(1):13-24. Avaliable from: https://www.sciencedirect.com/science/article/pii/ S095965260100018X

BRASIL. ANEEL. Agência Nacional de Energia Elétrica. Atlas de energia elétrica do Brasil. Brasília, 2008.

BRASIL. Decreto no 99.656, de 26 outubro de 1990. Dispõe sobre a criação, nos órgãos e entidades da Administração Federal direta e indireta, da Comissão Interna de Conservação de Energia (Cice), nos casos que menciona, e dá outras providências. Brasília (Brasil): Casa Civil, 1990.

BRASIL. Decreto no 1.927, de 8 de dezembro de 1993. Dispõe sobre a criação do Selo Verde de eficiência energética. Brasília (Brasil): Casa Civil, 1993.

BRASIL. Decreto no 3.330, de 6 de janeiro de 2000. Dispõe sobre a redução do consumo de energia elétrica em prédios públicos da Administração Pública Federal, e dá outras providências. Brasília (Brasil): Casa Civil, 2000.

BRASIL. Decreto 4.131, de 14 de fevereiro 2002. Dispõe sobre medidas emergenciais de redução do consumo de energia elétrica no âmbito da Administração Pública Federal. Brasília (Brasil): Casa Civil, 2002.

BRASIL. Decreto no 7.746, de 5 de junho de 2012. Regulamenta o art. 3 da lei no 8.666, de 21 de junho de 1993, para estabelecer critérios, práticas e diretrizes para a promoção do desenvolvimento nacional sustentável nas contratações realizadas pela administração pública federal, e institui a comissão interministerial de sustentabilidade na administração pública - CISAP. Brasília (Brasil): Casa Civil, 2012.

BRASIL. MINISTÉRIO DE MINAS E ENERGIA. Portaria $\mathrm{n}^{\circ}$ 113, de 15 de março de 2002. Brasília (Brasil): Ministério de Minas e Energia, 2002.

BRASIL. MINISTÉRIO DE MINAS E ENERGIA. Plano Nacional de Energia 2030. Brasília. 2007. Brasília (Brasil): Ministério de Minas e Energia, 2007.

BRASIL.MINISTÉRIO DE MINAS E ENERGIA. Plano Nacional de Eficiência Energética: Premissas e Diretrizes Básicas. Brasília. 2011. Brasília (Brasil): Ministério de Minas e Energia, 2011.

BRASIL. MINISTÉRIO DE MINAS E ENERGIA. Balanço Energético Nacional 2017. Relatório síntese. 2017. Rio de Janeiro (Rio de Janeiro): Empresa de Pesquisa Energética, 2017. 
BRASIL. MINISTÉRIO DE MINAS E ENERGIA, MINISTÉRIO DA INDÚSTRIA E DO COMÉRCIO (MME/MIC) Portaria Interministerial № 1.877, de 30 de Dezembro de 1985. Brasília (Brasil): Ministério de Minas e Energia, Ministério da Indústria e do Comércio, 1985.

BRASIL. MINISTÉRIO DO PLANEJAMENTO, DESENVOLVIMENTO E GESTÃO. Instrução Normativa no 10 , de 12 de novembro de 2012. Estabelece regras para elaboração dos Planos de Gestão de Logística Sustentável de que trata o art. 16, do Decreto no 7.746, de 5 de junho de 2012, e dá outras providências. Brasília (Brasil): Ministério do Planejamento, Desenvolvimento e Gestão, 2012.

BRASIL. MINISTÉRIO DO PLANEJAMENTO, DESENVOLVIMENTO E GESTÃO. Instrução Normativa no 02 , de 04 de junho de 2014. Dispõe sobre regras para a aquisição ou locação de máquinas e aparelhos consumidores de energia pela Administração Pública Federal direta, autárquica e fundacional, e uso da Etiqueta Nacional de Conservação de Energia (ENCE) nos projetos e respectivas edificações públicas federais novas ou que recebam retrofit. Brasília (Brasil): Ministério do Planejamento, Desenvolvimento e Gestão, 2012.

BRASIL. MINISTÉRIO DO PLANEJAMENTO, DESENVOLVIMENTO E GESTÃO. Portaria nำ 23, de 12 de fevereiro de 2015. Estabelece boas práticas de gestão e uso de Energia Elétrica e de Água nos órgãos e entidades da Administração Pública Federal direta, autárquica e fundacional e dispõe sobre o monitoramento de consumo desses bens e serviços. Brasília (Brasil): Ministério do Planejamento, Desenvolvimento e Gestão, 2015.

CAMPOS, Kemerson Cantero de. Plano de Gestão de Logística Sustentável com foco na Água e Esgoto: Uma Proposta Para A Universidade Federal De Mato Grosso Do Sul. (Dissertação). Mestrado Profissional em Administração Pública em Rede Nacional - PROFIAP, Escola de Administração e Negócios, Fundação Universidade Federal de Mato Grosso do Sul. Campo Grande (MS), 2018.

COllaÇO, F. M. A.; BERMANN, C. Perspectivas da Gestão de Energia em âmbito municipal no Brasil. Estudos Avançados. 2017;31(89):213-235.

COPE - Code of Conduct and Best Practice Guidelines for Journal Editors. Code of Conduct, (2011). Disponível em: <https://publicationethics.org/files/u7141/1999pdf13. pdf $>$. Acessado em: mar. 2018.

FERREIRA, Talita Guimarães de Oliveira. Políticas Públicas para o SAG da Bovinocultura de Corte. (Dissertação). Mestrado Profissional em Administração Pública em Rede, pela Escola de Administração e Negócios, da Fundação Universidade Federal de Mato Grosso do Sul. Campo Grande (MS), 2018.
FERREIRA, Fernando Machado et al. Water's quality and environmental conditions of the hydric resources in Grajaú-MA. Revista Ciência e Natura, v. 40, e66, p.1-8. Santa Maria (RS), dez, 2018.

FLICK, U. Introdução à metodologia de pesquisa: um guia para iniciantes. São Paulo: Penso Editora, 2013.

FONSECA NETO, Sebastião Nogueira da; FREITAS, Nívia Magalhães da Silva; FREITAS, Nádia Magalhães da Silva. Uma carta para o futuro: constructos sobre (in) sustentabilidade. Revista Ciência e Natura, v. 39, n. 1, p.133-141. Santa Maria (RS), jan-abr, 2017.

FRANCO, Samyra; MOURA-LEITE, Rosamaria Cox; CAMERON, Milena Missiano; JESUS-LOPES, José Carlos de e ALMEIDA, Vera Luci. Plano de Gestão de Logística Sustentável e Seus Indicadores: o conceito mínimo de divulgação, conscientização e capacitação nas universidades federais brasileiras. Revista Gestão Universitária na América Latina - Gual, Florianópolis (SC), v. 10, n.4, p. 204-226, Edição Especial.

GIL, Antonio. Carlos. Métodos e técnicas de pesquisa social. 6. ed. São Paulo: Atlas, 2008.

GUERRA, A.F.S. Ambientalização e sustentabilidade nas universidades: subsídios, reflexões e aprendizagens. Itajaí (SC): Univali, 2015.

HARRING, N.s; LUNDHOLM, C.; TORBJÖRNSSON, T. The effects of higher education in economics, law and political science on perceptions of responsibility and sustainability. Springer International Publishing; 2017.

IPEEC. Energy Efficiency Action Plan - Voluntary Collaboration in Energy Efficiency [Internet]. 2014. [cited 2017 abr 17]. Avaliable from: https://ipeec.org/upload/ publication_related_language/pdf/481.pdf

KRAUSE, C. B. et al. Manual de prédios eficientes em energia elétrica. Rio de Janeiro: IBAM/ELETROBRÁS/ PROCEL, 2002.

KIHARA, Bruna Megumi Takara. Compras, Contratações Sustentáveis e Materiais de Consumo do Plano de Gestão de Logística Sustentável: uma proposta para a Universidade Federal de Mato Grosso do Sul. (Dissertação). Mestrado Profissional em Administração Pública em Rede Nacional - PROFIAP, Escola de Administração e Negócios, Fundação Universidade Federal de Mato Grosso do Sul. Campo Grande (MS), 2018.

KIHARA, Bruna Megumi Takara.; MOURA-LEITE, Rosamaria Cox; JESUS-LOPES, José Carlos de. Compras e Contratações Sustentáveis das Universidades Federais Brasileiras. Revistafsa, Teresina (PI), v. 16, n.1, art.2, p. 27-53, jan/fev, 2019. 
LEITE, A. D. A energia do Brasil. 2. ed. Rio de Janeiro: Elsevier, 2013.

LO, K. Energy conservation in China's higher education institutions. Energy Policy. 2013;56:703-710.

LORI, Erfan Shamsaddini \& LEMAN, Zulkiflle. Renewable energy sources and analyzing the wind turbine performance; A Review. Revista Ciência e Natura, v. 38, n. 2, p.780-802. Santa Maria (RS), mai-ago, 2016.

MANSANO, S. R. V. O método qualitativo nos estudos sociais aplicados: dimensões éticas e políticas. Revista Economia \& Gestão. 2013;14(34):119-136.

MARCONI, M. A; LAKATOS, E. M. Fundamentos de metodologia científica. 5. ed. São Paulo: Atlas, 2003.

MARQUES, M. C. S. et al. Conservação de energia: eficiência energética de equipamentos e instalações. Itajubá: Fupai, 2006.

MARQUES, M. C. S. et al. Eficiência Energética: teoria \& Prática. Itajubá: FUPAI, 2007.

MENKES, M. Eficiência energética, políticas públicas e sustentabilidade [tese]. Brasília: Centro de Desenvolvimento Sustentável/Universidade de Brasília, 2004 .

MILANO, Jackson. Proposta de utilização de sistema híbrido eólico/solar de geração de energia em estabelecimentos comerciais na Ilha do Mel-PR. Revista Ciência e Natura, v. 40, e66, p.1-20. Santa Maria (RS), dez, 2018.

MONTEiRO, M. A. G.; ROCHA, L. R. R. Gestão Energética. Rio de Janeiro: Eletrobrás, 2005.

MORAES, R. Uma tempestade de luz: a compreensão possibilitada pela análise textual discursiva. Ciência \& Educação. 2003;9(2):191-211.

NOGUEIRA, Luiz Augusto Horta. Uso racional: a fonte energética oculta. Estudos Avançados. 2007;21(59):91-105.

NOGUEIRA, Mabel Valverde. A Qualidade de Vida no Trabalho sob o enfoque do Plano de Gestão de Logística Sustentável: uma proposta para a Universidade Federal de Mato Grosso do Sul. (Dissertação). Mestrado Profissional em Administração Pública em Rede Nacional - Profiap, Escola de Administração e Negócios, Fundação Universidade Federal de Mato Grosso do Sul. Campo Grande (MS), 2018.
NOGUEIRA, Mabel Valverde; MOURA-LEITE, Rosamaria Leite; JESUS-LOPES, José Carlos de. A qualidade de vida no trabalho; uma proposta de melhorias para o Plano de Gestão de Logística Sustentável da Universidade Federal de Mato Grosso do Sul. FACEP Pesquisa: Desenvolvimento e Gestão. v, 21, n.2 - miao/jun/jul/ ago 2018a.

PINTO JUNIOR, H. Q. (Org). Economia da energia: fundamentos econômicos, evolução histórica e organização industrial. São Paulo: Elsevier, 2016.

PROCEL. PROCEL EPP. Eficiência Energética nos Prédios Públicos [Internet]. 2006. [cited 2017 abr 18]. Avaliable from: http://www.procelinfo. com.br/data/Page s/LU M IS623F E 2 A 5 I T E M I D 5C0D828A5E894B4AA0280C96CCED1760PTBRIE.html.

PROCEL. Manual de Etiquetagem de Edificações Públicas [Internet]. 2014. [cited 2017 oct 17]. Avaliable from: http://189.9.150.57/assets/conteudo/midias/ manualetiquetedificpublicas20141010.pdf.

PRODANOV, C. C.; FREITAS, E. C. Metodologia do Trabalho Científico: Métodos e Técnicas da Pesquisa e do Trabalho Acadêmico. 2. ed. Novo Hamburgo: Editora Feevale, 2013.

PICCININI, M.S. Conservação de energia na indústria: as políticas adotadas na época da crise energética. Revista do BNDES.1994;1(2).

PUCRS. Manual de Economia de Energia USE - Uso Sustentável de Energia. Porto Alegre: PUCRS, 2010.

RISSATO, Pedro Henrique Sant'Ana. Ações Propostas pelas Universidades Federais Brasileiras, em Relação à Coleta Seletiva, a partir de suas Práticas no Plano de Gestão De Logística Sustentável e a Experiência da UFMS. (Dissertação). Mestrado Profissional em Administração Pública em Rede Nacional - Escola de Administração e Negócios da Fundação Universidade Federal de Mato Grosso do Sul (UFMS). Campo Grande (MS), 2018.

RISSATO, Pedro Henrique Sant'Ana. A análise das práticas de coleta seletiva, no âmbito das universidades federais Brasileiras. Revista Ciência e Natura. v. 40, e66, p. 1-19. Santa Maria (RS), dez, 2018a.

SECCHI, Leonardo. Políticas Públicas: conceitos, esquemas de análise, casos práticos. 2. ed. São Paulo: Cengage Learning, 2013.

TAUCHEN, Joel; BRANDLI, Luciana Londero. A gestão ambiental em instituições de ensino superior: modelo para implantação em campus universitário. Gestão e Produção. 2006;13(3):503-515. 
TRIVIÑOS, A.N.S. Introdução à pesquisa em ciências sociais: a pesquisa qualitativa em educação. São Paulo: Atlas, 1987.

VILLALVA. M.G. Energia solar fotovoltaica: conceitos e aplicações. 2. ed. São Paulo: Érica. 2015.

World Energy Council. Energy Efficiency: A Worldwide Review - Indicators, Policies, Evaluation. London: WEC, 2004.

\section{Contribuição dos autores}

\section{Elton Jorge da Silva}

Contribuições substanciais para a concepção do trabalho; aquisição; análise e interpretação de dados; redigiu o trabalho e realizou uma revisão substancial.

\section{José Carlos de Jesus Lopes}

Contribuições substanciais para a concepção do trabalho; análise e interpretação de dados; redigiu o trabalho e realizou uma revisão substancial.

\section{Rosamaria Cox Moura Leite Padgett}

Contribuições substanciais para a concepção do trabalho; análise e

interpretação de dados; redigiu o trabalho e realizou uma revisão

substancial.

Jeovan de Carvalho Figueiredo

Redigiu o trabalho e realizou uma revisão substancial.

Erlaine Binotto

Redigiu o trabalho e realizou uma revisão substancial.

Frederico Fonseca da Silva

Redigiu o trabalho e realizou uma revisão substancial. 